\title{
JORNAL DE

\section{A abordagem do ciclo de políticas: explorando alguns desafios da sua utilização no campo da Política Educacional}

\section{The policy cycle approach: exploring some challenges of its use in the field of Education Policy}

\section{El enfoque del ciclo de políticas: explorando algunos desafíos de su utilización en el campo de la Política Educativa}

Citação: MAINARDES, J. A abordagem do ciclo de políticas: explorando alguns desafios da sua utilização no campo da Política Educacional. Jornal de Políticas Educacionais. V. 12, n. 16. Agosto de 2018.

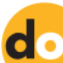

http://10.5380/jpe.v12i0.59217

\section{Resumo:}

A abordagem do ciclo de políticas, formulada pelo sociólogo inglês Stephen J. Ball e colaboradores, tem sido bastante empregada por pesquisadores de Política Educacional, políticas curriculares, entre outros campos. 0 artigo tem por objetivo apresentar alguns desafios da utilização dessa abordagem, definidos a partir da leitura e da análise de trabalhos que a utilizam. 0 trabalho apresenta também uma síntese da abordagem do ciclo de políticas e da teoria da atuação (theory of policy enactment) e ainda uma análise do uso da abordagem do ciclo de políticas no Brasil.

Palavras-chave: Política educacional; Abordagem do ciclo de Políticas; Teoria da atuação.

\footnotetext{
Abstract:

The policy cycle approach, formulated by the English sociologist Stephen J. Ball and collaborators, has been widely used by researchers of Education Policy, curricular policies, among other fields. This paper aims to present some challenges of using this approach, defined from the reading and the analysis of the works that use it. The paper also presents a synthesis of the policy cycle approach and the theory of policy enactment, as well as an analysis of the use of the policy cycle approach in Brazil.

Keywords: Education policy; Policy cycle approach; Theory of enactment.

Resumén:

${ }^{1}$ Doutor em Educação (UCL - Institute of Education). Professor e pesquisador do Programa de PósGraduação em Educação da Universidade Estadual de Ponta Grossa (UEPG). E-mail: jefferson.m@uol.com.br
} 
El enfoque del ciclo de políticas, formulado por el sociólogo inglés Stephen J. Ball y colaboradores, ha sido muy empleado por investigadores de Política Educativa, políticas curriculares, entre otros campos. El artículo tiene por objetivo presentar algunos desafíos de la utilización de este enfoque, definidos a partir de la lectura y el análisis de trabajos que la utilizan. El trabajo también presenta una síntesis del enfoque del ciclo de políticas y de la teoría de la actuación y un análisis del uso del enfoque del ciclo de políticas en Brasil.

Palabras clave: Política educativa; Enfoque del ciclo de políticas; Teoría de la actuación.

\section{Introdução}

O objetivo deste trabalho é apresentar alguns desafios da utilização da abordagem do ciclo de políticas (policy cycle approach), a qual vem sendo empregada por um número significativo de pesquisadores brasileiros, principalmente do campo da Política Educacional e dos estudos de políticas curriculares. Tais desafios foram formulados a partir da leitura e da análise de trabalhos de autores brasileiros (artigos, teses e dissertações) que empregaram a referida abordagem.

0 trabalho está dividido em quatro seções. Em um primeiro momento, apresentase uma breve exposição da abordagem do ciclo de políticas. Em seguida, apresenta-se a teoria da atuação (theory of policy enactment) e o uso da abordagem no Brasil. Finalmente, são indicados alguns desafios da sua utilização pelos pesquisadores.

\section{Breve exposição da abordagem do ciclo de políticas}

A abordagem do ciclo de políticas (policy cycle approach), desenvolvida pelo sociólogo inglês Stephen J. Ball e colaboradores (BOWE; BALL; GOLD, 1992; BALL; BOWE, 1992; BALL, 1994), foi formulada inicialmente no final da década de 1980 e início da década de 1990, no contexto de uma pesquisa sobre a "implementação" do currículo nacional inglês, a partir de $1988^{2}$.

Inicialmente, Ball e Bowe (1992) tentaram caracterizar o processo político, introduzindo a noção de um ciclo contínuo constituído por três facetas ou arenas políticas: a política proposta, a política de fato e a política em uso. A primeira faceta, a "política proposta", referia-se à política oficial, relacionada às intenções não somente do governo e de seus assessores, departamentos educacionais e burocratas encarregados de "implementar" políticas, mas também intenções das escolas, das autoridades locais e de outras arenas onde as políticas emergem. A "política de fato" constituía-se pelos textos políticos e textos legislativos que dão forma à política proposta e são as bases iniciais para

\footnotetext{
2 O Education Reform Act (Ato de Reforma Educacional) estabeleceu, em outras questões, a ideia de
} currículo nacional para a Inglaterra, País de Gales e Irlanda do Norte (ENGLAND, 200-). 
que as políticas sejam colocadas em prática. Por último, a "política em uso" referia-se aos discursos e às práticas institucionais que emergem do processo de implementação das políticas pelos profissionais que atuam no nível da prática.

Em seguida, porém, Stephen Ball e Richard Bowe romperam com essa formulação inicial porque a linguagem utilizada apresentava uma certa rigidez que eles não desejavam empregar para delinear o ciclo de políticas. Para eles, há uma variedade de intenções e de disputas que influenciam o processo político, e aquelas três facetas ou arenas apresentavam-se como conceitos restritos, opondo-se ao modo pelo qual eles queriam representar o processo político. No livro Reforming education and changing schools, publicado em 1992, Bowe e Ball apresentaram uma versão mais refinada do ciclo de políticas. Nesse livro, eles rejeitam os modelos de política educacional que separam as fases de formulação e de implementação porque eles ignoram as disputas e os embates sobre a política e reforçam a racionalidade do processo de gestão. Os autores consideram que os profissionais que atuam nas escolas não são totalmente excluídos dos processos de formulação ou implementação de políticas e usam os dois estilos de textos considerados por Roland Barthes (writerly e readerly) para distinguir em que medida os profissionais que atuam na escola são envolvidos nas políticas. Um texto readerly (ou prescritivo) limita o envolvimento do leitor ao passo que um texto writerly (ou escrevível) convida o leitor a ser coautor do texto, encorajando-o a participar mais ativamente na interpretação do texto. Um texto readerly limita a produção de sentidos pelo leitor que assume um papel de "consumidor inerte" (HAWKES, 1977, p. 114). Em contraste, um texto writerly envolve o leitor como coprodutor, como um intérprete criativo. 0 leitor é convidado a preencher as lacunas do texto.

Os autores propuseram um ciclo contínuo constituído por três contextos principais: o contexto de influência, o contexto da produção de texto e o contexto da prática. Esses contextos estão inter-relacionados, não têm uma dimensão temporal ou sequencial e não são etapas lineares. Cada um desses contextos apresenta arenas, lugares e grupos de interesse e cada um deles envolve disputas e embates (BOWE; BALL; GOLD, 1992).

Em 1994, a partir de uma série de críticas feitas à abordagem, no livro Education reform: a critical and post-structural approach, Ball (1994) expandiu o ciclo de políticas acrescentando outros dois contextos ao referencial original: o contexto dos resultados (efeitos) e o contexto da estratégia política. 0 quarto contexto do ciclo de políticas - o 
contexto dos resultados ou efeitos - preocupa-se com questões de justiça, de igualdade e de liberdade individual. A ideia de que as políticas têm efeitos, em vez de simplesmente resultados, é considerada mais apropriada. Nesse contexto, as políticas deveriam ser analisadas em termos do seu impacto e das interações com desigualdades existentes. Esses efeitos podem ser divididos em duas categorias: gerais e específicos. Os efeitos gerais da política tornam-se evidentes quando aspectos específicos da mudança e dos conjuntos de respostas (observadas na prática) são agrupados e analisados. 0 último contexto do ciclo de políticas é o contexto de estratégia política. Esse contexto envolve a identificação de um conjunto de atividades sociais e políticas que seriam necessárias para lidar com as desigualdades criadas ou reproduzidas pela política investigada. Segundo Ball (1994), esse é um componente essencial da pesquisa social crítica e do trabalho daqueles que Foucault chama de "intelectuais específicos", o qual é produzido para uso estratégico em embates e situações sociais específicas.

Em uma entrevista publicada em 2009, Stephen Ball sugeriu que esses dois últimos contextos podem ser explorados dentro dos contextos primários. 0 contexto dos resultados/efeitos está relacionado ao contexto da prática, e o contexto das estratégias políticas pode ser explorado no contexto de influência (MAINARDES; MARCONDES, 2009).

\section{A teoria da atuação das políticas (theory of policy enactment)}

Um fato importante no contexto da abordagem do ciclo de políticas foi a publicação do livro How school do policy (BALL; MAGUIRE; BRAUN, 2012) ${ }^{3}$. Nesse livro, os autores apresentam a teoria da atuação (theory of policy enactment). Os autores desenvolveram de forma mais aprofundada uma ideia anunciada na formulação inicial da abordagem do ciclo de políticas: as políticas não são meramente implementadas, mas sujeitas a processos de recontextualização, recriação.

0 termo enactment é de difícil tradução. Tradicionalmente, essa palavra tem sido usada no contexto legal para descrever o processo de aprovação de leis e de decretos. No livro de 2012, os autores a utilizam no sentido teatral, referindo-se à noção de que o ator possui um texto que pode ser apresentado/representado de diferentes formas. 0 texto, no entanto, é apenas uma pequena parte (porém, uma parte importante) da produção. Os

\footnotetext{
${ }^{3} \mathrm{O}$ livro foi traduzido para a Língua Portuguesa - Como as escolas fazem as políticas: atuação em escolas secundárias (BALL; MAGUIRE; BRAUN, 2016).
} 
autores usam esse termo para indicar que as políticas são interpretadas e materializadas de diferentes e variadas formas. Os atores envolvidos (no caso, os professores ou outros sujeitos envolvidos no processo de atuação das políticas) têm o controle do processo e não são "meros implementadores" das políticas. Para a Língua Portuguesa, "policy enactment" pode ser entendido como "encenação", “colocar em ação" ou atuação.

Ball assim explica o conceito de atuação:

[...] a atuação da política é mais uma vez uma tentativa de escapar do confinamento da teorização modernista arrumada, ordenada e agradável, focada particularmente na noção de implementação. E eu queria apagar implementação da linguagem da pesquisa em política, fazer disto um pária por causa das suposições epistemológicas, empíricas e teóricas que o termo carrega consigo. A política é "implementada" ou a "implementação" falha, a política é fixada no texto, algo que alguém escreve e planeja, e outra pessoa a "implementa", ou não. 0 que eu queria fazer era substituir isto com a noção de atuação e ver a atuação, de um lado, como um processo criativo, no qual o produto do processo de atuação é algo diferente daquilo que estava escrito no texto. Mas também, por outro lado, reconhecendo que a atuação é em parte produzida discursivamente, que as possibilidades de se pensar e falar sobre políticas são na verdade articuladas dentro dos limites de certas possibilidades discursivas. Então, ao mesmo tempo, era uma tentativa de liberar o ator político como este agente criativo na produção de políticas, mas reconhecendo que os alcances destas possibilidades criativas são, ao menos em parte, construídos em outros lugares, dentro do discurso. A atuação é local, contingencial e algumas vezes frágil. A política "entra" nos contextos, ela não destrói eles - para parafrasear Anthony Giddens. (AVELAR, 2016, p. 6).

Os autores argumentam que as políticas são colocadas em ação em condições materiais, com recursos variados, em relação a determinados "problemas". As políticas são definidas contra e ao lado de compromissos, valores e formas de experiência existentes. Um quadro da atuação das políticas precisará considerar um conjunto de condições objetivas em relação a um conjunto de dinâmicas "interpretativas" subjetivas. Assim, “[...] o material, o estrutural e o relacional precisam ser incorporados na análise de políticas, a fim de compreender melhor as atuações das políticas no âmbito institucional" (BALL; MAGUIRE; BRAUN, 2016, p. 21). Na análise de políticas, faz-se necessário considerar uma série de dimensões contextuais: contextos situados; culturas profissionais; contextos materiais e contextos externos. Essas dimensões são bastante úteis para a análise de políticas, uma vez que orientam o pesquisador para identificar os aspectos intervenientes no processo de colocar as políticas em ação, no contexto da prática. 
Assim, a atuação de políticas envolve processos criativos de interpretação e de recontextualização - ou seja, a tradução de textos em ação e as abstrações de ideias políticas em práticas contextualizadas - e esse processo envolve "interpretações de interpretações" (RIZVI; KEMMIS, 1987 apud BALL; MAGUIRE; BRAUN, 2016). No contexto da atuação, utilizam-se dos conceitos de interpretação e de tradução.

A interpretação é o processo de buscar compreender a política. Geralmente é realizada por atores com cargos de autoridade (diretores, inspetores, coordenadores), os quais preveem significados e também "peneiram detritos da política" (BALL, em entrevista a AVELAR, 2016). Já a tradução é um processo produtivo e criativo. Envolve a criação de estratégias para colocar uma política em ação.

Para Ball, Maguire e Braun (2016), a interpretação "[...] é uma leitura inicial, um fazer sentido da política - o que este texto significa para nós? O que nós temos de fazer? Nós temos de fazer alguma coisa? É uma leitura política e substancial - uma 'decodificação', que é ao mesmo tempo retrospectiva e prospectiva (BALL, 1993)”. (BALL; MAGUIRE; BRAUN, 2016, p. 68).

Para Freeman (apud LENDVAI; STUBBS, 2012), a tradução

[...] transfere e transforma: ela implica em representar algo de uma nova maneira e em um novo lugar, inevitavelmente mudando o que isto significa. É uma "arte do comprometimento", uma arte não uma ciência, e implica mediação entre diferentes reivindicações. Acima de tudo, é mais do que uma interpretação: ela é ativa, produtiva e criativa. (FREEMAN apud LENDVAI; STUBBS, 2012, p. 16).

Ball, Maguire e Braun (2016) explicam que a tradução é uma espécie de "terceiro espaço" entre política e prática. É um processo iterativo de fazer textos institucionais e colocar esses textos em ação, literalmente "atuar" sobre a política

[...] usando táticas que incluem conversas, reuniões, planos, eventos, "caminhadas de aprendizagem", bem como a produção de artefatos e empréstimo de ideias e práticas de outras escolas, a compra e a utilização de materiais comerciais e sites oficiais, sendo apoiado por conselheiros da autoridade local. (BALL; MAGUIRE; BRAUN, 2016, p. 69-70, grifo dos autores).

Nas formulações iniciais do ciclo de políticas, Ball (1994) já mencionava a importância de os pesquisadores identificarem os "ajustamentos secundários" que eram desenvolvidos pelos professores e demais atores envolvidos com a política. Indicava também que, muitas vezes, os pesquisadores falhavam em identificar tais ajustamentos. 
A teoria da atuação oferece conceitos e elementos mais concretos para a identificação dos processos de interpretação e de tradução dentro de dimensões contextuais objetivas. Alguns exemplos bem-sucedidos do uso da teoria da atuação são as pesquisas de Alferes (2017) e Pereira (2017). Nessas pesquisas, observou-se que as dimensões contextuais da teoria da atuação contribuíram para a coleta de dados no contexto da prática, bem como para a análise dos dados e apresentação dos resultados. Ao lado disso, essas dimensões contextuais ofereceram elementos teóricos para identificar e analisar as interpretações, as traduções e as adaptações realizadas no contexto da prática, o qual é compreendido como um espaço de "produção" de soluções e alternativas para tentar fazer algo com a política proposta.

\section{A utilização da abordagem do ciclo de políticas no Brasil}

A abordagem do ciclo de políticas vem sendo utilizada em diferentes países, como um "método para a análise de políticas". Alguns autores utilizam-na, na sua íntegra, explorando os contextos principais do ciclo de políticas: influência, produção e contexto da prática. Outros exploram alguns de seus contextos ou empregam conceitos que foram desenvolvidos no âmbito das discussões da abordagem (política como texto, política como discurso, crítica à noção de "implementação" de políticas, o contexto da prática como espaço de produção de políticas, etc.).

No Brasil, no final da década de 1990, alguns trabalhos de Stephen J. Ball já eram citados. 0 uso da abordagem do ciclo de políticas em pesquisas brasileiras data do início dos anos 2000, quando começou a ser utilizada por pesquisadores e pós-graduandos da Universidade do Estado do Rio de Janeiro (UERJ), especialmente por Elizabeth Macedo e Alice Casimiro Lopes. ${ }^{4}$

Em 2006, foi publicada, em Língua Portuguesa, uma síntese da abordagem do ciclo de políticas (MAINARDES, 2006). As entrevistas com Stephen J. Ball trouxeram elementos para a compreensão de suas ideias (MAINARDES; MARCONDES, 2009; MAINARDES, 2015; AVELAR, 2016). Além disso, há textos que dialogam com a abordagem e seus fundamentos teóricos (OLIVEIRA; LOPES, 2011; LOPES, 2016; MACEDO, 2016) e outros que discutem as contribuições da abordagem para a pesquisa em Políticas Educacionais

\footnotetext{
4 Entre as pesquisas que utilizaram o ciclo de políticas em uma fase inicial, pode-se citar: Morgado (2003), Lopes (2004), Destro (2004), Macedo (2006).
} 
(MAINARDES; GANDIN, 2013a, 2013b) e para a pesquisa sobre políticas de currículo (LOPES; MACEDO, 2011).

A abordagem do ciclo de políticas tem despertado o interesse de pesquisadores da área de Educação, principalmente vinculados aos campos de Política Educacional e Currículo. Mainardes e Stremel (2015) apresentam um levantamento de 145 trabalhos que utilizaram a abordagem do ciclo de políticas (livro, capítulos de livros, artigos, teses e dissertações). Em uma consulta ao "Catálogo de Teses e Dissertações" da CAPES (abril de 2018) 5 com o termo "ciclo de políticas", foram obtidos 359 resultados, sendo 100 Teses e 259 Dissertações (217 de Mestrado acadêmico e 42 de Mestrado Profissional), nas áreas de Educação, Ensino, Administração, Administração Pública e Linguística. Já na Biblioteca Digital Brasileira de Teses e Dissertações (BDTD), do Instituto Brasileiro de Informação em Ciência e Tecnologia (IBICT)', a busca como termo "abordagem do ciclo de políticas" resultou em 117 resultados.

Há, pelo menos, duas hipóteses para o interesse pelo uso da abordagem do ciclo de políticas. A primeira é o fato de que a abordagem se constitui em um método para a análise de políticas (MAINARDES; MARCONDES, 2009), oferecendo elementos teóricometodológicos para o desenvolvimento da pesquisa, bem como da sua exposição (estruturação textual). Embora possa parecer simples, a abordagem do ciclo de políticas é um referencial complexo, que demanda diversas investigações e ainda a adoção de um referencial teórico que dê sustentação para a análise de políticas específicas.

A segunda hipótese é a de que a literatura em Língua Portuguesa sobre referenciais teórico-metodológicos para a análise de políticas é ainda restrita. Assim, a existência de textos introdutórios, em Língua Portuguesa sobre o ciclo de políticas, facilita a sua disseminação entre os pesquisadores do campo da Política Educacional. Todavia, deve-se destacar que as lacunas do processo da formação de pesquisadores, principalmente no que se refere ao domínio das matrizes epistemológicas e das perspectivas teóricas que são mais comumente utilizadas na pesquisa em Educação, podem conduzir à adoção de perspectivas teóricas sem o devido aprofundamento de suas bases epistemológicas e ontológicas. Pode também levar a uma utilização acrítica, apressada ou equivocada.

\footnotetext{
${ }^{5}$ Disponível em: <http://catalogodeteses.capes.gov.br/catalogo-teses/\#!/>.

${ }^{6}$ Disponível em: <http://bdtd.ibict.br/vufind/>.
} 
A partir das formulações do enfoque dos Estudos Epistemológicos de Política Educacional - EEPE (TELLO, 2012), argumenta-se, neste trabalho, que a abordagem do ciclo de políticas, em muitos casos, é empregada de forma limitada, sem explorar de forma satisfatória as possibilidades que a abordagem oferece. Isso pode ser observado, por exemplo, quando o pesquisador menciona que fará uso da abordagem, mas não a utiliza como um elemento integrador da pesquisa, em termos de coerência entre perspectiva teórico-epistemológica, metodologia, análise e conclusões. Em outras palavras, a abordagem do ciclo de políticas não é empregada como epistemetodologia. No contexto dos estudos epistemológicos de Política Educacional, são indicados três elementos principais: a perspectiva epistemológica, o posicionamento epistemológico e o enfoque epistemetodológico ${ }^{7}$. Este último refere-se essencialmente à ideia de que a metodologia empregada deve decorrer, em uma pesquisa coerente, dos pressupostos teóricoepistemetológicos assumidos, os quais conduzem também a um determinado tipo de posicionamento epistemológico. Segundo Mainardes (2017), o enfoque epistemetodológico

[...] é o modo como se constrói metodologicamente a pesquisa a partir de uma determinada perspectiva epistemológica e de um posicionamento epistemológico. Refere-se ao nível de coerência entre os diferentes aspectos da pesquisa (objetivos, referencial teórico, metodologia, análises, conclusões). Nenhuma metodologia é neutra. Por essa razão, ao explicitar suas bases epistemológicas, o pesquisador pode exercer a vigilância epistemológica em sua pesquisa, cuja construção parte da perspectiva e do posicionamento epistemológicos assumidos. 0 sentido de reunir as palavras epistemologia e metodologia deseja representar que a metodologia da pesquisa decorre das orientações epistemológicas do pesquisador. 0 enfoque epistemetodológico pode ser compreendido como o fio condutor que articula todos os elementos da pesquisa, ampliando sua coerência, consistência e rigorosidade. (MAINARDES, 2017, p. 4).

\section{Alguns desafios para utilizar a abordagem do ciclo de políticas}

Nesta seção, a partir da leitura e da análise de pesquisas e de publicações brasileiras que utilizam a abordagem do ciclo de políticas, são apresentados alguns desafios da utilização dessa abordagem.

\footnotetext{
${ }^{7}$ A respeito desses conceitos, ver Tello (2012), Tello e Mainardes (2015), Mainardes e Tello (2016), Mainardes (2017).
} 
1ํ) Importância do domínio da abordagem e de seus fundamentos teórico-epistemológicos

As limitações identificadas na utilização da abordagem do ciclo de políticas em alguns trabalhos parecem estar relacionadas aos seguintes aspectos: a) desconhecimento da perspectiva teórico-epistemológica que orienta a formulação da abordagem, bem como das vinculações de Stephen J. Ball com a Sociologia das políticas (Policy Sociology); b) desconhecimento do fato de que Stephen J. Ball propôs mudanças na abordagem (1992, 1994, 2009, 2012) e que a teoria da atuação (2012) contribui sobremaneira para uma expansão da análise do contexto da prática; c) tendência ao uso apenas de traduções de textos de Ball disponíveis em Língua Portuguesa; e d) pouca interlocução com outras pesquisas que empregaram a abordagem do ciclo de políticas.

Na fase inicial, a abordagem foi desenvolvida a partir de pressupostos teóricos pósestruturalistas. Ao longo do tempo, Ball assumiu uma perspectiva epistemológica pluralista e, mais recentemente, Ball afirmou que “[...] usa métodos modernistas e depois os sujeita à teorização pós-estrutural. E esse jogo entre dados - de um tipo modernista, e teoria - de um tipo pós-estruturalista, eu considero muito produtivo" (AVELAR, 2016, p. 3). É importante que os pesquisadores interessados na abordagem tenham clareza da perspectiva epistemológica que fundamenta a abordagem, pois a ela estão associados um conceito/concepção de política e de política educacional e também a concepção de que diversos fatores influenciam a formulação de políticas, entre outros aspectos relevantes.

As ideias de Ball, incluindo a abordagem do ciclo de políticas, inscrevem-se no contexto da policy Sociology (sociologia das políticas educacionais), ou seja, o uso de teorias e métodos da sociologia para a análise de políticas. De modo geral, a sociologia das políticas pressupõe uma análise crítica das políticas (desde a sua formulação, produção do texto, atuação na prática, resultados e consequências); a necessidade de levar em consideração as consequências das políticas para classes sociais distintas; a importância de explicitar um conceito de política e de política educacional; bem como explicitar questões relacionadas ao Estado e seu papel na oferta educacional em geral e da política investigada, de modo mais específico (MAINARDES; ALFERES, 2014).

O uso adequado da abordagem do ciclo de políticas demanda ainda: a) levar em consideração que o contexto dos resultados/efeitos e o contexto da estratégia política podem ser analisados dentro dos contextos primários (entrevista de Ball a Mainardes e Marcondes, 2009); b) considerar as formulações de Ball, Maguire e Braun (2012/2016) sobre a teoria da atuação (theory of policy enactment), no livro Como as escolas fazem as 
MAINARDES, J. A abordagem do ciclo de políticas: explorando alguns desafios da sua utilização no campo da Política Educacional

políticas, as quais, de certo modo, expandem as explanações de Ball sobre o contexto da prática; c) considerar que Stephen J. Ball tem apresentado, em suas publicações, uma série de conceitos e de ideias, tais como: etnografia de redes; nova governança e redes; papel das redes sociais e das políticas no contexto de influência e de produção do texto; a necessidade de pensar sobre a base ontológica da política ${ }^{8}$; a importância de o pesquisador explicitar um conceito/concepção de política e de política educacional (o qual influencia todo o processo da pesquisa), entre outros conceitos relevantes.

\section{2º) Necessidade de um referencial teórico específico para fundamentar a análise}

Ball considera a abordagem do ciclo de políticas como um método para a análise de políticas educacionais (MAINARDES; MARCONDES, 2009). Constitui-se em uma ferramenta teórico-metodológica promissora para fundamentar a análise de políticas. No entanto, há necessidade de um referencial teórico mais específico para fundamentar a análise da política investigada. A análise de trabalhos que empregam a abordagem do ciclo de políticas indica que, em alguns casos, não há um referencial teórico propriamente dito, mas a utilização de ideias, de conceitos, de contribuições de autores, muitas vezes de matrizes epistemológicas distintas, constituindo o que McLennan (1996) chama de "teorização adicionada"9. Há, por outro lado, trabalhos que utilizam o ciclo de políticas com um referencial teórico mais articulado e coerente, seja pelo emprego da estratégia da teorização combinada ${ }^{10}$ ou pelo uso de uma teoria específica mais consolidada.

\footnotetext{
${ }^{8} \mathrm{~A}$ base ontológica da política está relacionada ao conceito de epistemologia profunda. Pensar sobre a base ontológica da política demanda refletir sobre questões abrangentes, tais como: Quais as finalidades da política? Para quem foram pensadas? Com base em quais pressupostos de sujeito, de sociedade, de educação? Quais as relações de poder envolvidas em todos os processos e espaços? Qual a nossa visão de mundo e de que forma ela interfere na análise de dados e na construção da epistemetodologia da pesquisa? Quais os valores que orientam as nossas análises e em que medida estes reforçam discursos e práticas das quais não compartilhamos? (ver entrevista de Ball - MAINARDES, 2015). A base ontológica da política pode ser explicada como apreensão da essência da política, aquilo que ela realmente é. Tal apreensão demanda ir além da descrição e análise, mas buscar atingir o nível da compreensão (MAINARDES; TELLO, 2016)

${ }^{9}$ A teorização adicionada caracteriza-se pelo emprego de ideias e de conceitos sem a devida coerência e convergência entre eles. Constitui-se pela adoção mais ou menos aleatória de teorias, de conceitos, de ideias de diferentes perspectivas epistemológicas, resultando em um conjunto de ideias e de conceitos sem coerência, unidade e articulação teórica. 0 simples adicionamento e a sobreposição de ideias de diferentes autores resultam em uma tentativa fracassada da definição de um referencial teórico, o qual pode ser considerado frágil, desarticulado e epistemologicamente pouco coerente (MAINARDES, 2017). ${ }^{10}$ A teorização combinada é um esforço de articular teorias ou conceitos oriundos de diferentes teorias, com o objetivo de compor um quadro teórico consistente para fundamentar uma determinada análise. Tal esforço demanda fazer escolhas teóricas e justificá-las, o que implica em um exercício de reflexividade e de vigilância epistemológica (MAINARDES, 2017).
} 
Em uma pesquisa caracterizada pela integração entre os elementos teóricoepistemológicos e metodológicos (epistemetodologia), é importante indicar as relações entre a abordagem do ciclo de políticas e o referencial teórico específico adotado para fundamentar a análise, bem como justificar as contribuições e o papel do ciclo de políticas e do referencial teórico específico na configuração da pesquisa.

Pesquisadores da Red de Estudios Teóricos y Epistemológicos en Política Educativa (ReLePe) têm argumentado a favor da relevância da explicitação da perspectiva epistemológica, bem como a importância de apresentar análises (autodeclarações) a respeito das combinações teóricas adotadas no estudo (TELLO, 2012; TELLO; MAINARDES, 2015; MAINARDES, 2017, 2018). A justificativa da argumentação em favor da explicitação da perspectiva epistemológica e das tentativas de articulação de teorias distintas fundamenta-se nos conceitos de vigilância epistemológica (Bachelard, Bourdieu) e do uso consciente e reflexivo das teorias. ${ }^{11}$ Por exemplo, Mainardes (2004), Gouveia (2011) e Alferes (2017) empregaram a abordagem do ciclo de políticas de forma articulada com a teoria de Basil Bernstein. Um ponto em comum destes estudos é a tentativa de explicitar os fundamentos epistemológicos da abordagem do ciclo de políticas (Ball) e da teoria de Bernstein, as possíveis inter-relações entre ambas e ainda a contribuição de cada uma na configuração do referencial teórico, na argumentação, análises, conclusões.

$\left.3^{\circ}\right)$ Necessidade de analisar os contextos do ciclo de políticas de forma abrangente, coerente e bem fundamentada

A utilização da abordagem do ciclo de políticas pressupõe uma caracterização (descrição) clara e objetiva da política investigada. Assim, é necessário apresentar dados variados, aspectos históricos, legislativos, contextuais, discursivos, político-ideológicos, custo financeiro, entre outros. Ball, Maguire e Braun (2016) enfatizam a importância do contexto, o qual deve ser levado a sério na análise da atuação das políticas.

A importância de uma teorização sobre Estado vem sendo debatida desde a formulação inicial da abordagem do ciclo de políticas. Os pesquisadores são desafiados a explicitar uma posição teórica acerca da concepção e do papel do Estado e de suas relações com a política investigada. Ball (1994) reconhece a importância da análise do

\footnotetext{
${ }^{11}$ A respeito do uso consciente e reflexivo, ver a entrevista de Ball (SANTOS, 2004) e GEWIRTZ (2007).
} 
Estado, afirmando que qualquer teoria decente de política educacional deve analisar o funcionamento e o papel do Estado. Contudo, "[...] qualquer teoria decente de política educacional não deveria limitar-se à perspectiva do controle estatal” (BALL, 1994, p. 10). Além de uma concepção de Estado, é importante que o pesquisador explicite sua concepção/conceito de política educacional, o qual necessita ser coerente com a concepção de Estado e com as demais opções teórico-epistemológicas da pesquisa.

A análise do contexto de influência é complexa. Há necessidade de considerar a historicidade da política investigada, pois geralmente políticas similares já foram propostas antes do surgimento de uma "nova política". É necessário explorar as escalas internacional/global, nacional, local.

Com relação à análise do contexto de produção de texto, um dos desafios principais refere-se à necessidade da análise crítica dos textos das políticas. Em muitos casos, a análise resulta em uma leitura "ingênua" dos textos e da própria política investigada. Algumas vezes, observa-se a crença de que os textos são coerentes e válidos, resultando em análises "aparentemente neutras" ou que tendem a legitimar as políticas investigadas. A explicitação de um conceito de política e de um posicionamento epistemológico pode auxiliar e enriquecer a análise dos textos. A análise crítica dos textos de políticas envolve: a) identificação da teoria do problema (que deu origem à política) e da teoria da política (seus fundamentos), bem como de possíveis desencontros e fragilidades tanto da teoria do problema quanto da teoria da política; b) análise discursiva dos textos para identificar seus fundamentos, ideologias subjacentes, incoerências, termos que se repetem; c) identificação das redes políticas e sociais envolvidas na formulação da política e dos seus textos; d) fundamentos teórico-epistemológicos explícitos ou implícitos (conceitos, autores), entre outros elementos.

A análise do contexto da prática demanda reunir uma quantidade significativa de dados. A teoria da atuação (e suas dimensões contextuais) contribui para a organização dos dados e para o refinamento da análise. Um aspecto importante é a permanente vigilância com relação à ideia de que as políticas não são "implementadas", que há a criação de ajustes secundários, traduções, interpretações, reinterpretações.

Alguns pesquisadores analisam o contexto dos resultados/efeitos da política (e.g. JOSLIN, 2018) e outros analisam tanto o contexto dos resultados/efeitos quanto o contexto de estratégia política (MAINARDES, 2004, 2007). Para Ball (1994), os resultados/efeitos decorrem do contexto da prática e estão muito relacionados à 
MAINARDES, J. A abordagem do ciclo de políticas: explorando alguns desafios da sua utilização no campo da Política Educacional

infraestrutura das escolas. Abordar esse contexto demanda apresentar evidências de naturezas diversas: análise de estatísticas, de relatórios oficiais; entrevistas com os responsáveis pelas políticas; entrevistas com sujeitos envolvidos na política; análise de observações do contexto da prática, etc. As pesquisas que intentam abordar esse contexto necessitam reunir dados abrangentes tanto no que se refere a mudanças na estrutura e na prática (efeitos de primeira ordem), quanto a mudanças nos padrões de justiça social, acesso e oportunidades sociais (efeitos de segunda ordem) (BALL, 1994).

O contexto da estratégia política envolve a identificação de um conjunto de atividades sociais e políticas que seriam necessárias para lidar com as desigualdades criadas ou reproduzidas pela política investigada. Envolve, portanto, um exercício propositivo a partir dos dados e constatações da pesquisa.

\section{Conclusões}

Neste trabalho, alguns desafios em utilizar a abordagem do ciclo de políticas nas pesquisas de Políticas Educacionais foram apresentados. Ao explorar os contextos do ciclo de políticas e a teoria da atuação (dimensões contextuais), os pesquisadores são desafiados a:

a) desenvolver problematizações abrangentes e fundamentadas, bem como a assumirem um posicionamento epistemológico crítico com relação à política investigada;

b) romper com análises mecanicistas e lineares, as quais entendem o processo político como racional e ordenado;

c) buscar realizar pesquisas analíticas e compreensivas ${ }^{12}$, ou seja, que extrapolem as tendências descritivas;

\footnotetext{
${ }^{12}$ Nas formulações sobre os níveis de abordagem/abstração (descrição, análise e compreensão), argumenta-se em favor da necessidade da ampliação do número de pesquisas de compreensão. 0 nível de compreensão é o nível mais elevado e avançado de abstração. Esse nível "[...] pode conter algum nível de descrição e um conjunto significativo de análises, os quais são subsumidos pela compreensão. São estudos que apresentam uma dupla dimensão do processo de pesquisa: explicar e compreender (o caráter interpretativo e explicativo). São estudos que buscam abordar a temática (teórica ou empírica) de modo mais totalizante, explorando de forma aprofundada as relações e as determinações envolvidas na política investigada ou na questão que está sendo discutida. De modo geral, são estudos que apresentam maior riqueza e profundidade nas análises, podendo inclusive servir de base para outras pesquisas. Nesses estudos, podemos observar uma articulação forte e coerente entre a perspectiva epistemológica, posicionamento epistemológico e enfoque epistemetodológico, mesmo quando a perspectiva epistemológica não é apresentada de forma explícita" (MAINARDES; TELLO, 2016, p. 8).
} 
d) buscar a geração de novos conceitos e categorias, em vez de mera aplicação de uma abordagem e de uma teoria ${ }^{13}$.

0 enfrentamento desses desafios exige, portanto, o uso consciente e reflexivo da abordagem do ciclo de políticas, o exercício da vigilância epistemológica, bem como a reflexão permanente dos limites da própria abordagem.

\section{Referências}

ALFERES, M. A. Pacto Nacional pela Alfabetização na Idade Certa: uma análise contextual da produção da política e dos processos de recontextualização. 2017. $246 \mathrm{f}$. Tese (Doutorado em Educação) - Universidade Estadual de Ponta Grossa, Ponta Grossa, 2017.

AVELAR, M. Entrevista com Stephen J. Ball: uma análise de sua contribuição para a pesquisa em Política Educacional. Archivos Analíticos de Políticas Educativas, v. 24, n. 24, p. 1-18, 2016.

BALL, S. J. Education reform: a critical and post structural approach. Buckingham: Open University Press, 1994.

BALL, S. J. Poder, conflito, micropolítica y todo li demás!. In: WALFORD, G. La outra cara de la investigación educativa. Madrid: Editorial La Muralla, 1995. p. 201-228.

BALL, S. J.; BOWE, R. Subject departments and the 'implementation' of National Curriculum policy: an overview of the issues. Journal of Curriculum Studies, v. 24, n. 2, p. 97-115, 1992.

BALL, S. J.; MAGUIRE, M.; BRAUN, A. How schools do policy: policy enactments in secondary schools. Abingdon: Routledge, 2012.

BALL, S. J.; MAGUIRE, M.; BRAUN, A. Como as escolas fazem as políticas: atuação em escolas secundárias. Tradução de Janete Bridon. Ponta Grossa: UEPG, 2016.

BOWE, R.; BALL, S. J.; GOLD, A. Reforming education \& changing schools: case studies in Policy Sociology. London: Routledge, 1992.

DESTRO, D. S. A política curricular em Educação Física do município de Juiz de Fora - MG: hibridismo entre o contexto de produção do texto político e o contexto da prática. 2004. 168 f. Dissertação (Mestrado em Educação) - Universidade do Estado do Rio de Janeiro, Rio de Janeiro, 2004.

ENGLAND. Department for Education. National Curriculum. [200-]. Disponível em: $<$ https://www.stem.org.uk/resources/collection/3166/national-curriculum>. Acesso em: 31 mar. 2018.

GEWIRTZ, S. A reflexividade ética na análise de políticas: conceituação e importância. Práxis Educativa, Ponta Grossa, v. 2, n. 1, p. 7 - 12, jan./jun. 2007.

\footnotetext{
13 A partir da proposta de Glaser e Strauss (1967) sobre a grounded theory (teoria fundamentada nos dados), compreende-se que o papel da pesquisa não é apenas aplicar uma teoria (teoria de cima para baixo), mas gerar teoria a partir dos dados (teoria de baixo para cima). Ball (1995) também sugere que o papel da pesquisa (etnográfica, qualitativa) não é fazer generalizações, mas gerar conceitos, categorias.
} 
GLASER, B.; STRAUSS, A. The discovery of grounded theory: strategies for qualitative research. New York: Aldine, 1967.

GOUVEIA, K. R. Política Educacional do Proeja: implicações na prática pedagógica. 2011. 300 f. Tese (Doutorado em Educação) - Centro de Educação, Universidade Federal de Pernambuco, Recife, 2011.

HAWKES, T. Structuralism and semiotics. London: Methuen, 1977.

JOSLIN, M. A. Políticas públicas de Educação Especial e a perspectiva inclusiva: o impacto em escolas da Rede Municipal de ensino de Ponta Grossa - PR. 2018. 188 f. Tese (Doutorado em Educação) - Universidade Federal do Paraná, Curitiba, 2018.

LENDVAI, N.; STUBBS, P. Políticas como tradução: situando as políticas sociais transnacionais. Práxis Educativa, Ponta Grossa, v. 7, n. 1, p. 11-31, jan./jun. 2012.

LOPES, A. C. Políticas curriculares: continuidade ou mudança de rumos? Revista Brasileira de Educação, São Paulo, v. 1, n. 26, p. 109-118, maio/ago. 2004.

LOPES, A. C. A teoria da atuação de Stephen Ball: E se a noção de discurso fosse outra? Archivos Analíticos de Políticas Educativas, v. 24, n. 25, p. 1-19, 2016.

LOPES, A.; MACEDO, E. Contribuições de Stephen Ball para o estudo de políticas de currículo. In: BALL, S.; MAINARDES, J. (Orgs.). Políticas educacionais: questões e dilemas. São Paulo: Cortez, 2011. p. 249-283.

MACEDO, E. F. Currículo: cultura, política e poder. Currículo sem Fronteiras, v. 6, n. 2, p. 98-113, jul./dez. 2006.

MACEDO, E. Por uma leitura topológica das políticas curriculares. Archivos Analíticos de Políticas Educativas, v. 24, n. 26, p. 1-23, 2016.

MAINARDES, J. Moving away from a graded system: a policy analysis of the Cycles of Learning Project (Brazil). $240 \mathrm{f}$. Thesis (PhD). Institute of Education - University of London, London, 2004.

MAINARDES, J. Abordagem do ciclo de políticas: uma contribuição para a análise de políticas educacionais. Educação \& Sociedade, Campinas, v. 27, n. 94, p. 47-69, jan./abr. 2006.

MAINARDES, J. Reinterpretando os ciclos de aprendizagem. São Paulo: Cortez, 2007.

MAINARDES, J. Entrevista com o Professor Stephen J. Ball. Olh@res, Guarulhos, v. 3, n. 2, p. 161-171, 2015.

MAINARDES, J. A pesquisa sobre política educacional no Brasil: análise de aspectos teórico-epistemológicos. Educação em Revista, Belo Horizonte, v. 33, p. 1- 25, 2017.

MAINARDES, J. A pesquisa no campo da política educacional: perspectivas teóricoepistemológicas e o lugar do pluralismo. Revista Brasileira de Educação, Rio de Janeiro, v. 23, 2018.

MAINARDES, J.; ALFERES, M. A. Sociologia das políticas educacionais: contribuições de Roger Dale. Atos de Pesquisa em Educação, Blumenau, v. 9, n. 2, p. 392-416, maio/ago. 2014.

MAINARDES, J.; GANDIN, L. A. A abordagem do ciclo de políticas como epistemetodologia: usos no Brasil e contribuições para a pesquisa sobre políticas educacionais. In: TELLO, C.; 
ALMEIDA, M. L. P. (Org.). Estudos epistemológicos no campo da pesquisa em política educacional. Campinas: Mercado de Letras, 2013a. p. 143-167.

MAINARDES, J.; GANDIN, L. A. Contributions of Stephen J. Ball to the research on educational and curriculum policies in Brazil. London Review of Education, v. 11, n. 3, 256-264. 2013b.

MAINARDES, J.; MARCONDES, M. I. Entrevista com Stephen J. Ball: um diálogo sobre justiça social, pesquisa e política educacional. Educação \& Sociedade, Campinas. v. 30, n. 106, p. 303-318, 2009.

MAINARDES, J.; STREMEL, S. Informações sobre a abordagem do ciclo de políticas. Disponível em: Downloads - Abordagem do ciclo de políticas - Stephen Ball. Ponta Grossa: UEPG, 2015. Disponível em: <www.uepg.br/gppepe>. Acesso em: 9 abr. 2018.

MAINARDES, J.; TELLO, C. A pesquisa no campo da política educacional: explorando diferentes níveis de abordagem e abstração. Archivos Analíticos de Políticas Educativas, v. 24, n. 75, p. 1-16, 2016.

MCLENNAN, G. Post-Marxism and the "four sins" of modernist theorizing. New Left Review, v. 218, p. 53-74, 1996.

MORGADO, V. N. A multieducação e a cultura no contexto da prática. 2003. $156 \mathrm{f}$. Dissertação (Mestrado em Educação) - Universidade do Estado do Rio de Janeiro, Rio de Janeiro, 2003.

OLIVEIRA, A.; LOPES, A. C. A abordagem do ciclo de políticas: uma leitura pela teoria do discurso. Cadernos de Educação, Pelotas, n. 38, p. 19-41, jan./abr. 2011.

PEREIRA, R. I. Redesenho curricular no Programa Ensino Médio Inovador: recontextualizações da política. 2017. 145 f. Dissertação (Mestrado em Educação) Universidade Regional de Blumenau - FURB, Blumenau, 2017.

SANTOS, L. L. de C. P. Stephen Ball e a educação (entrevista a Lucíola Licínio de C. P. Santos). Educação em Revista, Belo Horizonte, n. 40, p. 11- 25, dez. 2004.

TELLO, C. Las epistemologías de la política educativa: vigilancia y posicionamiento epistemológico del investigador en política educativa. Práxis Educativa, Ponta Grossa, v. 7, n. 1, p. 53-68, jun. 2012.

TELLO, C.; MAINARDES, J. Revistando o enfoque das epistemologias da política educacional. Práxis Educativa, Ponta Grossa, v. 10, n. 1, p. 153-178, jan./jun. 2015. 


\section{JORNAL DE POLÍTICAS EDUCACIONAIS

\section{SOMERIGHIS RESERVED}

O Copyright é retido pelo/a autor/a (ou primeiro co-autor) que outorga o direito da primeira publicação ao Jornal de Políticas Educacionais. Mais informação da licença de CreativeCommons encontram-se em http://creativecommons.org/licenses/by-nc-nd/2.5. Qualquer outro uso deve ser aprovado em conjunto pelo/s autor/es e pelo periódico.

JoRnal DE Políticas EduCACIONAIS é uma publicação do Núcleo de PolíticasEducacionaisdo Setor de Educação da Universidade Federal do Paraná - NuPE/UFPR, em consórcio com a Linha de Pesquisa em Políticas Educacionais do Programa de Pós-Graduação em Educação - PPGE/UFPR, que aceita colaboração, reservando-se o direito de publicar ou não o material espontaneamente enviado à redação. As colaborações devem ser enviadas ao NuPE/UFPR, conforme orientações contidas nas páginas do periódico na internet: http://revistas.ufpr.br/ipe.

Indexação:

BBE - Biblioteca Brasileira de Educação (MEC/INEP)

Clase (Base de Datos Bibliográfica de Revistas de Ciencias Sociales y Humanidades)

Diadorim - Diretório de Política de Acesso Aberto das Revistas Científicas Brasileiras (IBICT) Google Scholar

Index Copernicus

Portal de Periódicos (CAPES)

SER - Sistema Eletrônico de Revistas da Universidade Federal do Paraná (SER/UFPR)

Sumários de Revistas Brasileiras (FUNPEC-RP)

DRJI - Directory of Research Journals Indexing

(Periódico integralmente disponível apenas em via eletrônica)

Jornal de Políticas Educacionais / Núcleo de Políticas Educacionais da Universidade Federal do Paraná NuPE/UFPR - v.1, n. 1 (1ํo semestre de 2007) - Curitiba: NuPE/UFPR.

Volume 12, número 16 - Agosto de 2018

ISSN 1981-1969

1. Educação - Periódicos. 2. Política Educacional - Periódicos. I. NuPE/UFPR

Comitê Editorial:

Elisângela Scaff (UFPR)

Ana Lorena Bruel (UFPR)

Marcos Alexandre Ferraz (UFPR)

Conselho Editorial:

Andréa Barbosa Gouveia (UFPR), Ângela Hidalgo (UNICENTRO), Ângelo Ricardo de Souza (UFPR), Cesar GernominoTello (Universidad Nacional TresFebrero, Argentina),Gladys Beatriz Barreyro (USP), Juca Gil (UFRGS), Jefferson Mainardes (UEPG), João Ferreira de Oliveira (UFG), Luiz Souza Júnior (UFPB), Marcos Edgard Bassi (UFSC), Regina Maria Michelotto (UFPR), Robert Verhine (UFBA), Rosana Cruz (UFPI), Rubens 
MAINARDES, J. A abordagem do ciclo de políticas: explorando alguns desafios da sua utilização no campo da Política Educacional

Barbosa Camargo (USP), Sebastián Donoso Díaz (Universidad de Talca, Chile), Taís Moura Tavares (UFPR), TheresaAdrião (UNICAMP), Vera Peroni (UFRGS).

\author{
Jornal de Políticas Educacionais \\ Universidade Federal do Paraná \\ Setor de Educação \\ Núcleo de Políticas Educacionais - NuPE/UFPR \\ Rua Gal. Carneiro, 460 - 4o andar - Sala 407/C \\ 80.060-150 - Curitiba - PR - Brasil \\ Tel.: 41-3360-5380 \\ jpe@ufpr.br \\ http://revistas.ufpr.br/jpe
}

